\title{
Factors associated with anxiety and depression in hospitalized patients with first episode of acute myocardial infarction
}

\author{
Angeliki Alexandri, Elpida Georgiadi, Paschalia Mattheou, Maria Polikandrioti
}

Intensive Care Units and Emergency Nursing, Athens, Greece

Submitted: 1 September 2017

Accepted: 29 October 2017

Arch Med Sci Atheroscler Dis 2017; 2: e90-e99

DOI: https://doi.org/10.5114/amsad.2017.72532

Copyright @ 2017 Termedia \& Banach

\begin{abstract}
Introduction: Evaluation of anxiety and depression in cardiac patients is an area of nursing practice that is frequently neglected. The aim of the study was to explore anxiety and depression in hospitalized patients with their first episode of acute myocardial infarction.

Material and methods: The study sample included 148 hospitalized patients who had a first episode of acute myocardial infarction. Data collection was performed by the interview method using a specially designed questionnaire which included socio-demographic, clinical and other patients' characteristics as well as the Hospital Anxiety and Depression Scale (HADS) to assess patients' levels of anxiety and depression.

Results: Analysis of data showed that $52 \%$ and $38 \%$ of participants had high levels of anxiety and depression, respectively. Furthermore, anxiety levels revealed a statistically significant association with anxiolytics ( $p=$ $0.005)$ and antidepressant medication $(p=0.026)$ in hospital, the belief that they will face difficulties in relations with the social and family environment ( $p=0.009$ and $p=0.002$, respectively) and whether they considered themselves anxious $(p=0.003)$. Depression was statistically significantly associated with education level $(p=0.001)$, profession $(p=0.007)$, antidepressant medication in hospital $(p \leq 0.001)$, patients' relations with nursing staff $(p=0.019)$ and patients' belief that they will face difficulties in relations with the social and family environment ( $p \leq 0.001$ and $p \leq 0.001$, respectively).

Conclusions: The results showed that socio-demographic and clinical characteristics should be taken into serious consideration when exploring anxiety and depression in patients with a first episode of acute myocardial infarction in order to implement appropriate interventions.
\end{abstract}

Key words: first episode of acute myocardial infarction, anxiety, depression.

\section{Introduction}

Cardiovascular disease remains a global health issue despite the advances in medical treatment and in more accurate diagnosis. Significantly, cardiovascular diseases are responsible for more than 17.3 million deaths per year worldwide [1].

Patients diagnosed with a first episode of acute myocardial infarction experience an abrupt personal, family, societal and economic burden, which makes disease management more complicated [2]. As a consequence, patients may experience anxiety and depression that adversely affect the already established coronary disease $[3,4]$.

\author{
Corresponding author: \\ Maria Polikandrioti \\ Intensive Care Units \\ and Emergency Nursing \\ Athens, Greece \\ Phone: 003316972425054 \\ E-mail: mpolik2006@yahoo. \\ com
}


Though there is a significant association between anxiety/depression and myocardial infarction, the underlying pathophysiological mechanisms linking these two disease entities are not yet deeply understood. Possibly, the main mechanisms by which anxiety/depression exerts an impact on myocardial infarction are psychobiological, including alterations to the autonomous nervous system and immune system [5] as well as behavioral mechanisms including an unhealthy way of living, delay in seeking medical help, and failure in risk factor modification and in following treatment [6-9]. Unfortunately, anxiety and depression in cardiac patients are frequently underestimated and consequently undertreated [10-12].

Research studies frequently include in their evaluations patients with an acute heart attack who might have had a prior hospitalization due to the same reason or any other cardiac issue. Approximately $20 \%$ of patients with acute myocardial infarction have a history of a prior event [12]. More specifically, patients with myocardial infarction are more likely to have prior experience of hospitalization (45.5\%) compared to those with unstable angina (20.85\%) [9]. Additionally, depressive disorders increase the risk of re-hospitalization after acute myocardial infarction [13]. At the other end of the spectrum, prolonged hospitalization predicts readmission within 30 days in patients with an initial myocardial infarction [14]. Taking all the above findings into consideration, it is easily understandable that evaluating and thus treating anxiety and depression in patients with a first episode of acute myocardial infarction is essential to minimize re-hospitalizations and mortality.

The aim of the present study was to explore anxiety and depression in hospitalized patients with a first episode of acute myocardial infarction who had no prior hospitalization due to this cardiac problem.

\section{Material and methods}

\section{Participants}

The sample of the study consisted of 148 hospitalized patients diagnosed with a first episode of acute myocardial infarction. This sample was a convenience one. The study included hospitalized patients from 3 public hospitals in Athens, Greece during the period March 2016-June 2016.

During this period a total of 350 patients were hospitalized, but the present study enrolled only 148 who had no prior hospitalization due to a heart attack. The reason for not enrolling all patients was that subjects may have developed anxiety or depression due to their prior experience or the already established disease. Criteria for patients' inclusion in the study were: a) diagnosis of a first episode of acute myocardial infarction as assessed by the cardiologist, accompanied by a 12-lead electrocardiogram and indicative concentrations of cardiac markers detected in the blood, b) having no prior hospitalization due to the same reason, c) being a native speaker of the Greek language, and d) having been hospitalized for at least 2 days. All of the patients participated in the study on a voluntary basis and had their anonymity preserved.

All patients received conservative therapy and had no other disease.

Completion of questionnaires took place the third day of hospitalization in patient wards during the evening shift when all participants had no tasks to perform such as laboratory tests or clinical evaluations. In the present study there was no intervention group since this research merely recorded whether patients with a first episode of acute myocardial infarction experienced high levels of anxiety and depression and the associated factors. For this reason, we used HADS, which is commonly completed to determine the levels of anxiety and depression that a patient is experiencing.

\section{Ethical considerations}

Patients who met the entry criteria were informed by the researcher for the purposes of the study and participated only after they had given their written consent. All participants were informed of their rights to refuse or to discontinue their participation, according to the ethical standards of the Helsinki Declaration of 1983. The study was approved by the Medical Research Ethics Committee of each hospital.

\section{Data - variables}

Data collection was performed by the interview method using a questionnaire developed by the researchers which included socio-demographic and clinical characteristics, as well as other self-report variables. In detail: a) socio-demographic variables: gender, age, education level and job, b) clinical variables: medication with anxiolytics and antidepressants, duration of hospitalization, c) medical history variables: smoking, cigarettes per day, years of smoking, other person in family with heart problem, and d) self-report variables: patients' beliefs about the effect of illness on their family or social environment, concealment of the disease, consider themselves as anxious and relations with nursing staff.

\section{Assessment of anxiety and depression}

The Hospital Anxiety and Depression Scale (HADS), which was proposed in 1983 by Zigmond 
Table I. Patients' characteristics

\begin{tabular}{|c|c|}
\hline Parameter & Results \\
\hline Gender (male) & $87(58.78 \%)$ \\
\hline \multicolumn{2}{|l|}{ Age [years]: } \\
\hline$<56$ & $50(33.78 \%)$ \\
\hline $56-60$ & $38(25.68 \%)$ \\
\hline $61-70$ & $33(22.30 \%)$ \\
\hline$>70$ & $27(18.24 \%)$ \\
\hline \multicolumn{2}{|l|}{ Educational level: } \\
\hline Primary & $46(31.08 \%)$ \\
\hline Secondary & $63(42.57 \%)$ \\
\hline University & $39(26.35 \%)$ \\
\hline \multicolumn{2}{|l|}{ Job: } \\
\hline Employee & $60(40.54 \%)$ \\
\hline Unemployed/homemaker & $14(9.46 \%)$ \\
\hline Pensioner & $74(50.00 \%)$ \\
\hline $\begin{array}{l}\text { Medication with anxiolytics (in hospital) } \\
\text { (yes) }\end{array}$ & $80(54.05 \%)$ \\
\hline $\begin{array}{l}\text { Medication with anti-depressants } \\
\text { (in hospital) (yes) }\end{array}$ & $23(15.54 \%)$ \\
\hline Smoker (yes) & $77(52.03 \%)$ \\
\hline $\begin{array}{l}\text { Other person in family with heart } \\
\text { problem (yes) }\end{array}$ & $91(61.49 \%)$ \\
\hline Duration of hospitalization [days] $]^{\S}$ & $4(3-6)$ \\
\hline Cigarettes per day ${ }^{\S}$ & $20(15-30)$ \\
\hline Years of smoking§ & $30(25-35)$ \\
\hline \multicolumn{2}{|l|}{ Relations with nursing staff: } \\
\hline Very good & $77(52.03 \%)$ \\
\hline Good & $52(35.14 \%)$ \\
\hline Moderate/bad & $19(12.84 \%)$ \\
\hline \multicolumn{2}{|c|}{ Difficulties in relations with social environment: } \\
\hline Many & $46(31.08 \%)$ \\
\hline Fewer & $51(34.46 \%)$ \\
\hline None & $51(34.46 \%)$ \\
\hline \multicolumn{2}{|c|}{ Difficulties in relations with family environment: } \\
\hline Many & $47(31.76 \%)$ \\
\hline Fewer & $47(31.76 \%)$ \\
\hline None & $54(36.49 \%)$ \\
\hline Are you hiding your health problem? (yes) & $30(20.27 \%)$ \\
\hline Do you consider yourself anxious? (yes) & $114(77.03 \%)$ \\
\hline
\end{tabular}

${ }^{\S}$ Data presented as median (interquartile range).
Snaith [15] was used to evaluate depression and anxiety of patients. The scale consists of 14 questions that assess how patients felt during the previous week (7 questions assess depression level and 7 assess anxiety level). Scores of 0-7 indicate no anxiety or depression, scores of 8-10 indicate moderate levels of anxiety or depression, and scores $>11$ indicate high levels of anxiety or depression. The HADS scale was translated and tested for its validity and reliability in the Greek population by Mistakidou et al. [16].

\section{Statistical analysis}

Categorical variables are presented as absolute and relative frequencies (percentages), and quantitative variables are presented as the median and interquartile range since they do not follow the normal distribution (tested with Kolmogorov-Smirnov test and Q-Q plots). To test the existence of an association between levels of anxiety/ depression and patients' characteristics the Kruskal-Wallis test and the $\chi^{2}$ test of independence were used. Multinomial logistic regression was performed to estimate the effect of patients' characteristics on the levels of anxiety/depression (dependent variable). The results are presented with the odds ratio (OR) and 95\% confidence interval. The level of statistical significance was set at $\alpha=0.05$. The analysis was performed with the statistical package SPSS, version 16 (SPSS Inc, Chicago, II, USA).

\section{Results}

\section{Descriptive characteristics}

From Table I it is observed that $59 \%$ of the participants were men, $31 \%$ had primary education, approximately $40 \%$ were over 60 years, and $50 \%$ were pensioners. Moreover, $54 \%$ were taking anxiolytics in hospital and $15.5 \%$ were taking antidepressants in hospital. Furthermore, 52\% were smokers while the median duration of hospitalization was 4 days. The majority of the participants reported to have very good relations with nursing staff (52\%). Additionally, the majority believed that they would face few or no difficulties in relations with the social and family environment (34\% and 36\% respectively). $20 \%$ reported that they were hiding the health problem from society, and $77 \%$ considered themselves anxious.

\section{Levels of anxiety/depression}

The results showed that $52.03 \%$ of patients had high levels of anxiety and $37.84 \%$ high levels of depression while $22.30 \%$ and $21.62 \%$ had moderate levels of anxiety and depression, respectively. Low levels of anxiety were experienced by 
$25.68 \%$ of participants. The majority of patients did not experience depression (40.54\%).

\section{Patients' characteristics and anxiety levels}

Table II presents the association between anxiety levels and patients' characteristics. Anxiety levels revealed a statistically significant association with medication with anxiolytics in hospital ( $p=0.005)$ and antidepressant medications in hospital $(p=0.026)$, the belief that they will face difficulties in relations with the social and family environment ( $p=0.009$ and $p=0.002$ respectively) and whether they considered themselves anxious ( $p=0.003)$.

Specifically, the percentage of patients taking anxiolytics in hospital was higher among those who had high levels of anxiety (63.64\%) than the percentages observed among those with

Table II. Comparison between patients' characteristics and anxiety levels*

\begin{tabular}{|c|c|c|c|c|}
\hline Characteristics & Low levels & $\begin{array}{c}\text { Moderate } \\
\text { levels }\end{array}$ & High levels & $P$-value \\
\hline \multicolumn{5}{|l|}{ Sex: } \\
\hline Male & $24(63.16 \%)$ & $19(57.58 \%)$ & $44(57.14 \%)$ & 0.816 \\
\hline Female & $14(36.84 \%)$ & $14(42.42 \%)$ & $33(42.86 \%)$ & \\
\hline \multicolumn{5}{|l|}{ Age: } \\
\hline$<56$ & $13(34.21 \%)$ & $9(27.27 \%)$ & $28(36.36 \%)$ & 0.680 \\
\hline $56-60$ & $10(26.32 \%)$ & $11(33.33 \%)$ & $17(22.08 \%)$ & \\
\hline $61-70$ & $10(26.32 \%)$ & $5(15.15 \%)$ & $18(23.38 \%)$ & \\
\hline$>70$ & $5(13.16 \%)$ & $8(24.24 \%)$ & $14(18.18 \%)$ & \\
\hline \multicolumn{5}{|l|}{ Educational level: } \\
\hline Primary & $10(26.32 \%)$ & $10(30.30 \%)$ & $26(33.77 \%)$ & 0.856 \\
\hline Secondary & 19 (50.00\%) & $14(42.42 \%)$ & $30(38.96 \%)$ & \\
\hline University & $9(23.68 \%)$ & $9(27.27 \%)$ & $21(27.27 \%)$ & \\
\hline \multicolumn{5}{|l|}{ Job: } \\
\hline Employee & $19(50.00 \%)$ & $12(36.36 \%)$ & $29(37.66 \%)$ & 0.256 \\
\hline Unemployed/homemaker & $5(13.16 \%)$ & $1(3.03 \%)$ & $8(10.39 \%)$ & \\
\hline Pensioner & $14(36.84 \%)$ & $20(60.61 \%)$ & $40(51.95 \%)$ & \\
\hline Medication with anxiolytics (in hospital) (yes) & $12(31.58 \%)$ & $19(57.58 \%)$ & $49(63.64 \%)$ & 0.005 \\
\hline Medication with anti-depressants (in hospital) (yes) & $1(2.63 \%)$ & $5(15.15 \%)$ & $17(22.08 \%)$ & 0.026 \\
\hline \multicolumn{5}{|l|}{ Difficulties in relations with social environment: } \\
\hline Many & $5(13.16 \%)$ & $7(21.21 \%)$ & $34(44.16 \%)$ & 0.009 \\
\hline Fewer & $17(44.74 \%)$ & $12(36.36 \%)$ & $22(28.57 \%)$ & \\
\hline None & $16(42.11 \%)$ & $14(42.42 \%)$ & $21(27.27 \%)$ & \\
\hline \multicolumn{5}{|l|}{ Difficulties in relations with family environment: } \\
\hline Many & $5(13.16 \%)$ & $12(36.36 \%)$ & $30(38.96 \%)$ & 0.002 \\
\hline Fewer & $9(23.68 \%)$ & $12(36.36 \%)$ & $26(33.77 \%)$ & \\
\hline None & $24(63.16 \%)$ & $9(27.27 \%)$ & $21(27.27 \%)$ & \\
\hline Are you hiding your health problem? (yes) & $8(21.05 \%)$ & $6(18.18 \%)$ & $16(20.78 \%)$ & 0.944 \\
\hline Do you consider yourself anxious? (yes) & $24(63.16 \%)$ & $22(66.67 \%)$ & $68(88.31 \%)$ & 0.003 \\
\hline Duration of hospitalization [days] $]^{\S}$ & $4(3-6)$ & $5(3-6)$ & $4(3-5.5)$ & 0.683 \\
\hline
\end{tabular}

${ }^{\S}$ Data presented as median (interquartile range), *associations were tested for all characteristics in Table I, but here not all of them are presented. 
moderate and low levels of anxiety $(57.58 \%$ and $31.58 \%)$. The percentage of patients taking antidepressants in the hospital was higher among those who had high levels of anxiety (22.08\%) compared to that observed among those with moderate and low levels of anxiety $(15.15 \%$ and $2.63 \%$ respectively). The percentage of patients who believed they would experience many difficulties in the social and family environment was higher among those who had high levels of anxiety $(44.16 \%$ and $38.96 \%$ respectively) than that observed among those with moderate and low levels of anxiety. Finally, patients who considered themselves anxious had a higher percentage of high levels of anxiety (88.31\%) compared to those who did not (11.69\%).

\section{Patients' characteristics and depression levels}

Table III presents the association between depression and patients' characteristics. Depression is statistically significantly associated with education level $(p=0.001)$, profession $(p=0.007)$, with the antidepressant medication in hospital ( $p \leq$ $0.001)$, the patients' relations with nursing staff ( $p=0.019)$ and the beliefs of patients that they will face difficulties in relations with the social and family environment $(p \leq 0.001$ and $p \leq 0.001$, respectively).

More specifically, it was observed that patients with primary and secondary education had a higher percentage of high levels of depression $(42.86 \%$, and $42.86 \%$, respectively) compared to patients with a university level of education (14.29\%). In addition, employees and unemployed patients had a lower percentage of high levels of depression $(30.36 \%$ and $10.71 \%$ respectively) compared to pensioners (58.93\%). Patients taking antidepressants in the hospital had a lower percentage of high levels of depression (33.93\%) than that observed among those not taking them (66.07\%).

Patients who had very good relations with the nursing staff had a higher percentage of low levels of depression (68.33\%) while patients who had moderate or bad relationships with the nursing staff had a higher percentage of high depression levels (23.21\%). In addition, patients who believed they would face many difficulties in the social and family environment had higher percentages of high levels of depression $(53.57 \%$ and $53.57 \%$, respectively) compared to those who reported that they would face few difficulties.

\section{Effect of patients' characteristics on levels of anxiety}

Multinomial logistic regression was performed in order to assess the effect of independent fac- tors that remain statistically significantly associated with anxiety and depression.

From Table IV it is can be observed that patients who believed they would not face any difficulties in their family environment or did not consider themselves anxious had $87 \%$ and $79 \%$ less chance, respectively, of experiencing moderate and high levels of anxiety, respectively, compared to those facing many difficulties $(\mathrm{OR}=0.13, \mathrm{OR}=$ 0.21 and $p=0.015, p=0.010$, respectively).

\section{Effect of patients' characteristics on levels of depression}

Regarding the levels of depression (Table V), patients who had secondary level education or believed that they would not face any difficulties in their family environment had $89 \%$ and $94 \%$ less chance respectively of experiencing moderate levels of depression compared to those with primary level education or those who believed that they would face many difficulties ( $O R=0.11, \mathrm{OR}=0.06$ and $p=0.003, p=0.001$, respectively). In addition, patients who had secondary or university level of education had $85 \%$ and $87 \%$ respectively less chance of experiencing high levels of depression compared to those with primary level $(\mathrm{OR}=0.15$, $\mathrm{OR}=0.13$, and $p=0.005, p=0.009$, respectively).

Pensioner patients had a 7.19 times higher chance of experiencing moderate levels of depression compared to employees $(\mathrm{OR}=7.19$, $p=0.017$ ). Finally, patients who believed that they would not face any difficulties or just a few in their family environment had $88 \%$ and $82 \%$ less chance of experiencing high levels of depression compared to those who believed that they would face many difficulties $(\mathrm{OR}=0.12, \mathrm{OR}=0.18$ and $p=0.005, p=$ 0.016 , respectively). It was similar for patients who believed that they would not face any difficulties or just a few in their social environment $(O R=0.15$, $\mathrm{OR}=0.24$ and $p=0.015, p=0.037$ respectively).

\section{Discussion}

The present study showed that $20.27 \%$ of the participants reported concealing their health problem. This is an interesting finding that may reflect the deeper personal meaning that patients invest in their experiences. According to relevant studies, patients' perceptions about myocardial infarction may affect treatment, and expectations or efforts for recovery as well as participation in rehabilitation programs $[17,18]$.

The data also showed that $52.03 \%$ of participants experienced high levels of anxiety and $37.84 \%$ high levels of depression. A similar prior study which included 222 patients with ST segment elevation myocardial infarction who were hospitalized in both cardiac units and cardiology 
Table III. Comparison between patients' characteristics and depression levels*

\begin{tabular}{|c|c|c|c|c|}
\hline Characteristics & Low levels & Moderate levels & High levels & $P$-value \\
\hline \multicolumn{5}{|l|}{ Sex: } \\
\hline Male & $38(63.33 \%)$ & $18(56.25 \%)$ & $31(55.36 \%)$ & 0.648 \\
\hline Female & $22(36.67 \%)$ & $14(43.75 \%)$ & $25(44.64 \%)$ & \\
\hline \multicolumn{5}{|l|}{ Age: } \\
\hline$<56$ & $27(45.00 \%)$ & $10(31.25 \%)$ & $13(23.21 \%)$ & 0.177 \\
\hline $56-60$ & $14(23.33 \%)$ & $6(18.75 \%)$ & $18(32.14 \%)$ & \\
\hline $61-70$ & $11(18.33 \%)$ & $10(31.25 \%)$ & $12(21.43 \%)$ & \\
\hline$>70$ & $8(13.33 \%)$ & $6(18.75 \%)$ & $13(23.21 \%)$ & \\
\hline \multicolumn{5}{|l|}{ Educational level: } \\
\hline Primary & $8(13.33 \%)$ & $14(43.75 \%)$ & $24(42.86 \%)$ & 0.001 \\
\hline Secondary & $30(50.00 \%)$ & $9(28.13 \%)$ & $24(42.86 \%)$ & \\
\hline University & $22(36.67 \%)$ & $9(28.13 \%)$ & $8(14.29 \%)$ & \\
\hline \multicolumn{5}{|l|}{ Job: } \\
\hline Employee & $35(58.33 \%)$ & $8(25.00 \%)$ & $17(30.36 \%)$ & 0.007 \\
\hline Unemployed/homemaker & $5(8.33 \%)$ & $3(9.38 \%)$ & $6(10.71 \%)$ & \\
\hline Pensioner & $20(33.33 \%)$ & $21(65.63 \%)$ & $33(58.93 \%)$ & \\
\hline $\begin{array}{l}\text { Medication with anxiolytics } \\
\text { (in hospital) (yes) }\end{array}$ & $28(46.67 \%)$ & $18(56.25 \%)$ & $34(60.71 \%)$ & 0.304 \\
\hline $\begin{array}{l}\text { Medication with anti- } \\
\text { depressants (in hospital) } \\
\text { (yes) }\end{array}$ & $1(1.67 \%)$ & $3(9.38 \%)$ & $19(33.93 \%)$ & $<0.001$ \\
\hline \multicolumn{5}{|l|}{ Relations with nursing staff: } \\
\hline Very good & $38(63.33 \%)$ & $15(46.88 \%)$ & $24(42.86 \%)$ & 0.019 \\
\hline Good & $20(33.33 \%)$ & $13(40.63 \%)$ & $19(33.93 \%)$ & \\
\hline Moderate/bad & $2(3.33 \%)$ & $4(12.50 \%)$ & $13(23.21 \%)$ & \\
\hline \multicolumn{5}{|c|}{ Difficulties in relations with social environment: } \\
\hline Many & $7(11.67 \%)$ & $9(28.13 \%)$ & $30(53.57 \%)$ & $<0.001$ \\
\hline Fewer & $24(40.00 \%)$ & $11(34.38 \%)$ & $16(28.57 \%)$ & \\
\hline None & $29(48.33 \%)$ & $12(37.50 \%)$ & $10(17.86 \%)$ & \\
\hline \multicolumn{5}{|c|}{ Difficulties in relations with family environment: } \\
\hline Many & $6(10.00 \%)$ & $11(34.38 \%)$ & $30(53.57 \%)$ & $<0.001$ \\
\hline Fewer & $18(30.00 \%)$ & $16(50.00 \%)$ & $13(23.21 \%)$ & \\
\hline None & $36(60.00 \%)$ & $5(15.63 \%)$ & $13(23.21 \%)$ & \\
\hline $\begin{array}{l}\text { Are you hiding your health } \\
\text { problem? (yes) }\end{array}$ & $11(18.33 \%)$ & $7(21.88 \%)$ & $12(21.43 \%)$ & 0.888 \\
\hline $\begin{array}{l}\text { Do you consider yourself } \\
\text { anxious? (yes) }\end{array}$ & 45 (75.00\%) & 25 (78.13\%) & 44 (78.57\%) & 0.888 \\
\hline $\begin{array}{l}\text { Duration of hospitalization } \\
\text { [days] }]^{\S}\end{array}$ & $4.5(3.5-6)$ & $4(3-5.5)$ & $4(3-6)$ & 0.693 \\
\hline
\end{tabular}

${ }^{5}$ Data presented as median (interquartile range), ${ }^{*}$ associations were tested for all characteristics in Table I, but here not all of them are presented. 
Table IV. Effect of patients' characteristics on levels of anxiety

\begin{tabular}{|c|c|c|c|c|}
\hline \multirow[t]{3}{*}{ Characteristics } & \multicolumn{4}{|c|}{ Anxiety levels (reference category: low levels) } \\
\hline & \multicolumn{2}{|c|}{ Moderate levels } & \multicolumn{2}{|c|}{ High levels } \\
\hline & OR $(95 \% \mathrm{Cl})$ & $P$-value & OR $(95 \% \mathrm{Cl})$ & $P$-value \\
\hline \multicolumn{5}{|l|}{ Sex: } \\
\hline Male & Ref. Cat. & & Ref. Cat. & \\
\hline Female & $1.42(0.48-4.18)$ & 0.522 & $1.28(0.48-3.37)$ & 0.611 \\
\hline \multicolumn{5}{|l|}{ Age: } \\
\hline$<56$ & Ref. Cat. & & Ref. Cat. & \\
\hline $56-60$ & $1.29(0.34-4.92)$ & 0.707 & $0.50(0.15-1.63)$ & 0.249 \\
\hline $61-70$ & $0.46(0.10-2.15)$ & 0.325 & $0.82(0.24-2.78)$ & 0.751 \\
\hline$>70$ & $2.11(0.43-10.29)$ & 0.424 & $1.24(0.31-5.09)$ & 0.758 \\
\hline \multicolumn{5}{|c|}{ Medication with anxiolytics (in hospital): } \\
\hline Yes & Ref. Cat. & & Ref. Cat. & \\
\hline No & $0.49(0.15-1.61)$ & 0.243 & $0.49(0.18-1.32)$ & 0.158 \\
\hline \multicolumn{5}{|c|}{ Medication with anti-depressants (in hospital): } \\
\hline Yes & Ref. Cat. & & Ref. Cat. & \\
\hline No & $0.26(0.02-2.96)$ & 0.275 & $0.37(0.04-3.21)$ & 0.345 \\
\hline \multicolumn{5}{|c|}{ Difficulties in relations with social environment: } \\
\hline Many & Ref. Cat. & & Ref. Cat. & \\
\hline Fewer & $0.94(0.19-4.63)$ & 0.948 & $0.25(0.06-1.10)$ & 0.061 \\
\hline None & $3.05(0.51-18.1)$ & 0.220 & $0.37(0.08-1.78)$ & 0.216 \\
\hline \multicolumn{5}{|c|}{ Difficulties in relations with family environment: } \\
\hline Many & Ref. Cat. & & Ref. Cat. & \\
\hline Fewer & $0.66(0.14-3.04)$ & 0.595 & $1.17(0.28-4.93)$ & 0.847 \\
\hline None & $0.13(0.03-0.67)$ & 0.015 & $0.33(0.08-1.41)$ & 0.136 \\
\hline \multicolumn{5}{|c|}{ Do you consider yourself anxious? } \\
\hline Yes & Ref. Cat. & & Ref. Cat. & \\
\hline No & $1.31(0.36-4.64)$ & 0.681 & $0.21(0.06-0.68)$ & 0.010 \\
\hline
\end{tabular}

departments showed that $35.8 \%$ of participants had high levels of anxiety and $16.4 \%$ of patients had major depression [10].

Anxiety and depression rates in patients with acute myocardial infarction may vary, globally. Therefore, the major issue is not merely to present their prevalence but to enhance awareness among health professionals about this comorbidity, since high levels of depression are associated with high morbidity and mortality [19, 20]. Given that the present study concerned patients with their first acute myocardial infarction, immediate evaluation of depression is important since it is associated with increased risk of new cardiovascular events [21].
Analysis of the data also revealed high levels of anxiety and depression in participants who believed that they would experience many difficulties within the family and social environment. Interestingly, relevant studies indicated the importance of defining these difficulties in patients' lives and summarized them as follows: a) inability to maintain prior relations, roles or other future goals in life, b) physical limitations imposed by the disease, and c) urgent modification of risk factors such as smoking cessation [22-24].

Determining difficulties as they are perceived by patients is essential to implement the best approach to treating the frequently encountered burden of anxiety and depression. In recognition of 
Table V. Effect of patients' characteristics on levels of depression

\begin{tabular}{|c|c|c|c|c|}
\hline \multirow[t]{3}{*}{ Characteristics } & \multicolumn{4}{|c|}{ Depression levels (reference category: low levels) } \\
\hline & \multicolumn{2}{|c|}{ Moderate levels } & \multicolumn{2}{|c|}{ High levels } \\
\hline & OR $(95 \% \mathrm{Cl})$ & $P$-value & OR $(95 \% \mathrm{Cl})$ & $P$-value \\
\hline \multicolumn{5}{|l|}{ Sex: } \\
\hline Male & Ref. Cat. & & Ref. Cat. & \\
\hline Female & $1.42(0.48-4.18)$ & 0.522 & $1.40(0.48-4.07)$ & 0.539 \\
\hline \multicolumn{5}{|l|}{ Age: } \\
\hline$<56$ & Ref. Cat. & & Ref. Cat. & \\
\hline $56-60$ & $1.29(0.34-4.92)$ & 0.707 & $2.40(0.65-8.88)$ & 0.188 \\
\hline $61-70$ & $0.46(0.10-2.15)$ & 0.325 & $1.01(0.19-5.25)$ & 0.992 \\
\hline$>70$ & $2.11(0.43-10.29)$ & 0.424 & $0.97(0.14-6.77)$ & 0.980 \\
\hline \multicolumn{5}{|l|}{ Educational level: } \\
\hline Primary & Ref. Cat. & & Ref. Cat. & \\
\hline Secondary & $0.11(0.03-0.47)$ & 0.003 & $0.15(0.04-0.53)$ & 0.005 \\
\hline University & $0.23(0.05-1.18)$ & 0.080 & $0.13(0.02-0.60)$ & 0.009 \\
\hline \multicolumn{5}{|l|}{ Job: } \\
\hline Employee & Ref. Cat. & & Ref. Cat. & \\
\hline $\begin{array}{l}\text { Unemployed/ } \\
\text { homemaker }\end{array}$ & $1.09(0.13-8.81)$ & 0.937 & $1.07(0.17-6.42)$ & 0.865 \\
\hline Pensioner & $7.19(1.42-36.23)$ & 0.017 & $3.68(0.87-15.58)$ & 0.077 \\
\hline \multicolumn{5}{|c|}{ Relations with nursing staff: } \\
\hline Very good & Ref. Cat. & & Ref. Cat. & \\
\hline Good & $0.68(0.21-2.26)$ & 0.537 & $0.57(0.19-1.69)$ & 0.319 \\
\hline Moderate/bad & $2.53(0.33-19.23)$ & 0.370 & $2.88(0.43-19.16)$ & 0.274 \\
\hline \multicolumn{5}{|c|}{ Difficulties in relations with social environment: } \\
\hline Many & Ref. Cat. & & Ref. Cat. & \\
\hline Fewer & $0.41(0.10-7.85)$ & 0.245 & $0.24(0.07-0.91)$ & 0.037 \\
\hline None & $0.74(0.15-3.74)$ & 0.720 & $0.15(0.03-0.69)$ & 0.015 \\
\hline \multicolumn{5}{|c|}{ Difficulties in relations with family environment: } \\
\hline Many & Ref. Cat. & & Ref. Cat. & \\
\hline Fewer & $0.45(0.11-1.96)$ & 0.294 & $0.18(0.05-0.72)$ & 0.016 \\
\hline None & $0.06(0.01-0.30)$ & 0.001 & $0.12(0.03-0.54)$ & 0.005 \\
\hline
\end{tabular}

this, many studies have tried to explore patients' difficulties. In particular, after this life-threatening event, both sexes are struggling hard to achieve balance in their everyday life [24, 25]. At the initial stage, spouses seem to need social support [26], while after the crisis, patients are wondering about the possibility of returning to previous sexual life [27]. Providing information about concerns associated with safety of sexual activity is a matter of great importance [28]. Time of return to work also shapes patients' perception about difficulties in the family and social environment. Time to return to work seems to vary globally, as in the United States patients return to work after 75 days, while in Europe they return after 3-6 months [29]. However, the majority of patients return to work in 2 or 3 months with the exception of occupations that involve intense physical requirements. 
In the present study, depression was associated with education level and profession. Depression in pensioners is partially explained by other contributing factors such as living alone, or not having a supportive environment.

Educational level is an important health determinant as low-educational individuals usually have low income or low socioeconomic status. Lower education indicates lower awareness of adopting a healthy lifestyle and lower preventive measures such as screening programs or frequent visits to general practitioners [30, 31]. Individuals with a low level of education constitute a high-risk population for atherosclerosis, which is attributed to their preferred life-style [32].

Prevalence of anxiety and depression following the first acute myocardial infarction creates the demand for early evaluation and treatment [22].

A valuable tool for health professionals in daily clinical practice is assessment of patients' needs [9].

The results should be interpreted with caution as they are limited by the method of convenience sampling. This method is not representative of all patients in Greece, thus limiting the generalizability of the results.

Also, the study was cross-sectional and collected data at one point in time, thus not allowing the causal relation between anxiety/depression and the first episode of acute myocardial infarction to be established and not allowing for changes over time.

In conclusion, according to the present study:

Anxiety was associated with: a) medication with anxiolytics and antidepressants in hospital, b) the patients' belief that they will face difficulties in relations with the social and family environment, and c) and whether patients considered themselves as anxious. Depression was associated with: a) socio-demographic characteristics (education level, profession), b) antidepressant medication in hospital, c) the patients' relations with nursing staff, and d) the patients' belief that they will face difficulties in relations with the social and family environment

Clinically, the present findings regarding levels of anxiety and depression may promote recognition and thus early treatment of this comorbidity in patients with their first cardiac episode. Additionally, it may foster a multidisciplinary health care team approach.

Based on the present findings, it is suggested that understanding of patient-related characteristics is fundamental when developing interventions that address and alleviate the psychological burden.

\section{Conflict of interest}

The authors declare no conflict of interest.
References

1. Mozaffarian D, Benjamin EJ, Go AS, et al. Heart disease and stroke statistics - 2015 update: a report from the American Heart Association. Circulation 2015; 131: e29-32.

2. McLaughlin TJ, Aupont O, Bambauer KZ, et al. Improving psychologic adjustment to chronic illness in cardiac patients. The role of depression and anxiety. J Gen Intern Med 2005; 20: 1084-90.

3. Huffman JC, Smith FA, Blais MA, Beiser ME, Januzzi JL, Fricchione GL. Recognition and treatment of depression and anxiety in patients with acute myocardial infarction. Am J Cardiol 2006; 98: 319-24.

4. Huffman JC, Smith FA, Blais MA, Januzzi JL, Fricchione Gl. Anxiety, independent of depressive symptoms, is associated with in-hospital cardiac complications after acute myocardial infarction. J Psychosom Res 2008; 65: 557-63.

5. Kala P, Hudakova N, Jurajda M, et al. Depression and anxiety after acute myocardial infarction treated by primary PCI. PLoS One 2016; 11: e0152367.

6. Bonnet F, Irving K, Terra JL, Nony P, Berthezène F, Moulin P. Anxiety and depression are associated with unhealthy lifestyle in patients at risk of cardiovascular disease. Atherosclerosis 2005; 178: 339-44.

7. Rieckmann N, Gerin W, Kronish IM, et al. Course of depressive symptoms and medication adherence after acute coronary syndromes: an electronic medication monitoring study. J Am Coll Cardiol 2006; 48: 2218-22.

8. Bunde J, Martin R. Depression and prehospital delay in the context of myocardial infarction. Psychosom Med 2006; 68: 51-7.

9. Polikandrioti M, Goudevenos J, Michalis LK, et al. Correlation between the type of acute coronary syndrome with the needs of hospitalized patients. Glob J Health Sci 2016; 8: 126-34

10. Polikandrioti M, Goudevenos J, Michalis LK, et al. Factors associated with depression and anxiety of hospitalized patients with ST segment elevation myocardia infarction (STEMI). Asian Acad Res J Multidiscipl 2014; 1: 458-75.

11. Ziegelstein RC, Kim SY, Kao D, et al. Can doctors and nurses recognize depression in patients hospitalized with an acute myocardial infarction in the absence of formal screening. Psychosom Med 2005; 67: 393-7.

12. Shen L, Shah BR, Nam A, et al. Implications of prior myocardial infarction for patients presenting with an acute myocardial infarction. Am Heart J 2014; 167: 840-5.

13. Tisminetzky M, McManus DD, Erskine N, et al. Thirty-day hospital readmissions in patients with non-ST-segment elevation acute myocardial infarction. Am J Med 2015; 128: $760-5$

14. Reese RL, Freedland KE, Steinmeyer BC, Rich MW, Rackley JW, Carney RM. Depression and re-hospitalization following acute myocardial infarction. Circ Cardiovasc Qual Outcomes 2011; 4: 626e33.

15. Zigmond AS, Snaith RP. The Hospital Anxiety and Depression Scale. Acta Psychiatr Scand 1983; 67: 361-70.

16. Mystakidou K, Tsilika E, Parpa E, Katsouda E, Galanos A, Vlahos L. The Hospital Anxiety and Depression Scale in Greek cancer patients: psychometric analyses and applicability. Support Care Cancer 2004; 12: 821-5.

17. Gassner LA, Dunn S, Piller N. Patients' interpretation of the symptoms of myocardial infarction: implications for cardiac rehabilitation. Intensive Crit Care Nurs 2002; 18: 342-54

18. French DP, Cooper A, Weinman J. Illness perceptions predict attendance at cardiac rehabilitation following 
acute myocardial infarction: a systematic review with meta-analysis. J Psychosom Res 2006; 61: 757-67.

19. Barth J, Schumacher M, Herrmann-Lingen C. Depression as a risk factor for mortality in patients with coronary heart disease: a meta-analysis. J Psychosom Med 2004; 66: 802-13.

20. Larsen KK. Depression following myocardial infarction: an overseen complication with prognostic importance. Dan Med J 2013; 60: B4689.

21. Strik JJ, Honig A, Maes M. Depression and myocardial infarction: relationship between heart and mind. Prog Neuropsychopharmacol Biol Psychiatry 2001; 25: 879-92.

22. Nunes S, Rego G, Nunes R. Difficulties of Portuguese patients following acute myocardial infarction: predictors of readmissions and unchanged lifestyles. Asian Nurs Res (Korean Soc Nurs Sci) 2016; 10: 150-7.

23. Kristofferzon ML, Löfmark R, Carlsson M. Striving for balance in daily life: experiences of Swedish women and men shortly after a myocardial infarction. J Clin Nurs 2007; 16: 391-401.

24. Condon C, McCarthy G. Lifestyle changes following acute myocardial infarction: patients perspectives. Eur J Cardiovasc Nurs 2006; 5: 37-44.

25. Kettunen S, Solovieva S, Laamanen R, Santavirta N. Myocardial infarction, spouses' reactions and their need of support. J Adv Nurs 1999; 30: 479-88.

26. Santavirta N, Kettunen S, Solovieva S. Coping in spouses of patients with acute myocardial infarction in the early phase of recovery. J Cardiovasc Nurs 2001; 16: 34-46.

27. Abramsohn EM, Decker C, Garavalia B, et al. "I'm not just a heart, I'm a whole person here": a qualitative study to improve sexual outcomes in women with myocardial infarction. J Am Heart Assoc 2013; 2: e000199.

28. Brännström $M$, Kristofferzon $M L$, Ivarsson $B$, et al. Sexual knowledge in patients with a myocardial infarction and their partners. J Cardiovasc Nurs 2014; 29: 332-9.

29. Babić Z, Pavlov M, Oštrić M, Milošević M, Misigoj Duraković $M$, Pintarić $H$. Reinitiating professional working activity after myocardial infarction in primary percutaneous coronary intervention networks era. Int J Occup Med Environ Health 2015; 28: 999-1010.

30. Thombs BD, de Jonge P, Coyne JC, et al. Depression screening and patient outcomes in cardiovascular care: a systematic review. JAMA 2008; 300: 2161-71.

31. Kautzky-Willer A, Dorner T, Jensby A, Rieder A. Women show a closer association between educational level and hypertension or diabetes mellitus than males: a secondary analysis from the Austrian HIS. BMC Public Health 2012; 12: 392.

32. Piotrkowska R, Dobosz M, Książek J, Halena G. Social, demographic and clinical characteristics of patients suffering from peripheral vascular disease treated surgically compared to patients treated with endovascular angioplasty. Arch Med Sci Atheroscler Dis 2017; 2: e9-15. 